\title{
AUTENTICIDADE, PRESTÍGIO E RIVALIDADE NO CONTEXTO DA CULTURA POPULAR 0 ENCONTRO CULTURAL DE LARANJEIRAS (SE)
}

Luciana de Araujo Aguiar (UFRJ)

Este artigo aborda os grupos folclóricos e a relação entre eles a partir dos critérios e categorias que os hierarquizam no contexto de sua participação no Encontro Cultural de Laranjeiras, festival folclórico realizado anualmente há 38 anos, na semana do dia 6 de janeiro na cidade de Laranjeiras (SE). A hierarquização dos grupos precipita os conflitos existentes entre eles e as tensões que os constituem e neles se desenvolvem.

ENCONTRO CULTURAL DE LARANJEIRAS, GRUPOS FOLCLÓRICOS, TAIEIRA, CACUMBI, CHEGANÇA.

AGUIAR, Luciana de Araujo. Autenticidade, prestígio e rivalidade no contexto da cultura popular : o Encontro Cultural de Laranjeiras (SE). Textos escolhidos de cultura e arte populares, Rio de Janeiro, v.10, n.1, p. 81-100, mai. 2013. 


\section{AUTHENTICITY, PRESTIGE AND RIVALRY IN POPULAR CULTURE CONTEXT \\ THE CULTURAL MEETING OF LARANJEIRAS (STATE OF SERGIPE)}

Luciana de Araujo Aguiar (UFRJ)

This article intends to approach folk groups and their interrelationships based on criteria and categories that hierarchize such groups in the context of their participation in the Cultural Meeting of Laranjeiras, a folk festival which has been held annually in the past 38 years on the week of January 6 th in the city of Laranjeiras (SE). The hierarchization of groups precipitates inner conflicts and tensions that constitute and are developed inside the groups.

CULTURAL MEETING OF LARANJEIRAS, FOLK GROUPS, TAIEIRA, CACUMBI, CHEGANÇA

AGUIAR, Luciana de Araujo. Autenticidade, prestígio e rivalidade no contexto da cultura popular : o Encontro Cultural de Laranjeiras (SE). Textos escolhidos de cultura e arte populares, Rio de Janeiro, v.10, n.1, p. 81-100, mai. 2013. 


\section{INTRODUÇÃO}

O Encontro Cultural de Laranjeiras pode ser visto como um festival folclórico que reúne intelectuais, políticos e entusiastas do folclore em torno da temática da cultura popular brasileira. Realizado anualmente há 36 anos, na semana do dia 6 de janeiro na cidade de Laranjeiras (SE), o Encontro se afirma como um dos maiores festivais de folclore e cultura popular do Brasil e é aqui abordado como um processo ritual e festivo articulado em torno da noção folclore. ${ }^{1}$

Além de um simpósio temático anual, no qual folcloristas e intelectuais se reúnem para debater questões relacionadas à cultura popular brasileira, o festival se promove pela apresentação de grupos folclóricos não só de Laranjeiras, mas também de outras cidades do Estado de Sergipe. $O$ evento inclui outras atividades, como apresentações de teatro e dança, exposição, oficinas de artesanato, concertos e, as que mais público atraem, shows noturnos.

O festival é evento que permanece no tempo, mas não de forma estática, já que está constantemente mudando, a exemplo do tema do simpósio, diferente a cada ano. Embora seja processo em permanente mudança, é constituído de partes que necessariamente devem acontecer, entre as quais a realização do simpósio temático, a abertura oficial, a apresentação de grupos folclóricos pelas ruas da cidade, a procissão do Dia de Reis e a louvação dos grupos folclóricos em homenagem a Nossa Senhora do Rosário e são Benedito.

Segundo seus realizadores, o Encontro Cultural de Laranjeiras se destaca por promover a cultura popular do município de Laranjeiras e do Estado de Sergipe. Nessa perspectiva, a presença dos chamados grupos folclóricos é essencial. Trata-se de grupos de danças consideradas tradicionais em função dos elementos que as compõem, entre eles canto, indumentária e coreografia.

O corpo é um dos principais instrumentos para a execução das danças. O corpo que dança não é só um instrumento técnico, mas também um meio de comunicação, uma linguagem que através da sua ação e performance comunica, sendo dessa forma eficaz. Conforme observa Thomas Turino (2008), música e dança estão muito frequentemente no centro de nossas mais profundas experiências pessoais e sociais.

Segundo Schechner (2006) "Performances marcam identidades, dobram o tempo, remodulam e adornam o corpo, e contam estórias. Performances - de arte, rituais, ou da vida cotidiana - são comportamentos restaurados, comportamentos duas vezes experenciados, ações realizadas para as quais as pessoas treinam e ensaiam". Porque possuem dimensões simbólicas e comunicativa expressivas, as performances produzem subjetividades. Segundo Turner (1987, p. 76), o 
termo performance completa uma experiência. A execução das chamadas danças folclóricas completa, assim, uma experiência que já foi evidenciada nas relações cotidianas dos fazedores das danças. A execução das danças formaliza ideias da ordem social e performativamente as instaura.

Apesar de reunidos numa mesma nomenclatura, "grupo folclórico", os diversos grupos folclóricos que se apresentam no Encontro Cultural de Laranjeiras possuem status simbólico diferenciado, dado pelo contexto do próprio Encontro Cultural. Abordo aqui os grupos folclóricos e a relação entre eles a partir dos critérios e categorias que os hierarquizam no contexto de sua participação no Encontro Cultural de Laranjeiras. A dimensão conflitiva própria da estrutura ritual aparece mais fortemente entre os grupos folclóricos. A hierarquização precipita os conflitos existentes entre eles e as tensões que os constituem e neles se desenvolvem. Mesmo que nesse contexto o conflito se estabeleça de maneira intensa, ainda assim ele não aparece de modo muito explícito.

\section{OS DE DENTRO E OS DE FORA}

Participam do Encontro grupos folclóricos de Laranjeiras e de outros municípios de Sergipe, todos contratados pela prefeitura de Laranjeiras. Em 2011 se apresentaram no Encontro Cultural 110 grupos, entre locais e de fora, cuja remuneração é diferente como aponta a fala do secretário de Cultura de Laranjeiras.

A gente paga para os grupos de Laranjeiras a mais do que a gente paga para os grupos que vêm de outras cidades (...). Este ano [2011] foi 2.000 reais os adultos e 1.500 os infantis, e os de fora 1.000 reais. Agora, a gente dá transporte, a gente dá alimentação (...) Os grupos daqui, fora esses 2.000 reais, eles recebem todo o material das roupas deles. Todos os anos eles recebem todo o material (...) Alguns grupos grandes, como o Bacamarteiros, por exemplo (...) recebem mais ou menos parecido com os grupos de Laranjeiras. Grupos como Bacamarteiros, Parafusos, são grupos tradicionais do Encontro Cultural, a Chegança de Itabaiana. São grupos que chegaram juntos desde o primeiro momento. São considerados para a gente grupos também de Laranjeiras (Irineu Fontes, entrevista, 14.1.2011; grifo meu).

Houve, porém, mudança na remuneração dos grupos de 2010 para 2011. Em 2010, a remuneração dos grupos locais era de 1.000 reais para os de crianças e 1.500 para os de adultos. Os de fora receberam, em 2010, entre 600 e 800 , dependendo de seu tamanho, pois os grupos recebem de acordo com o número de componentes. 
Há, dessa forma, uma diferença material e simbólica entre os grupos locais e aqueles de cidades ou municípios vizinhos. Alguns turistas notaram a diferença entre os grupos folclóricos. Uma fotógrafa de Recife chamou atenção para o envolvimento de alguns grupos com a comunidade, citando o Chegança como exemplo. Também observou que alguns grupos pareciam, nas palavras dela, estar lá "por obrigação", como alguns dos cortejos. Os grupos de Laranjeiras são, portanto, os mais valorizados.

No entanto, alguns de outros municípios são simbolicamente tão importantes para o Encontro Cultural como os locais, por exemplo, Bacamarteiros, ${ }^{2}$ de Carmópolis (SE), Parafusos, ${ }^{3}$ de Lagarto (SE) e Chegança, ${ }^{4}$ de Itabaiana (SE) citados pelo secretário de Cultura e por ele considerados "grupos também de Laranjeiras".

\section{OS DE DENTRO E OS DE DENTRO}

Também ocorre diferenciação entre os grupos folclóricos de Laranjeiras, embora simbólica, já que todos os grupos locais recebem a mesma quantia para participar do Encontro. Eu já tinha percebido essa diferença desde minha primeira ida ao Encontro, em 2008, e, em 2011, isso foi explicitado pelo secretário de Cultura do município, em entrevista a mim concedida, ao se referir à apresentação dos grupos de Laranjeiras em outros municípios do Estado de Sergipe:

Às vezes as pessoas dizem "só quero o grupo tal", mas às vezes o grupo tal não pode ir. A gente está colocando todos os grupos para se apresentarem, não só os grupos de ponta, que dizer, que alguns falam, né, os mais importantes.

\section{- Quais são os grupos de ponta?}

Os grupos mais importantes da cidade que as pessoas dizem, e que eu também concordo, é o São Gonçalo, ${ }^{5}$ o Samba de Pareia, ${ }^{6}$ a Chegança, o Cacumbi, ${ }^{7}$ a Taieira; ${ }^{8}$ esses são os grupos mais tradicionais. Na verdade para mim não são os grupos de ponta, são os grupos mais tradicionais da cidade, os grupos verdadeiramente da cultura popular. São os grupos tradicionais, são os grupos folclóricos; tem outros que são representações de grupos folclóricos, como os reisados, os guerreiros, mas que a gente trata todos do mesmo nível; mas para as pessoas que gostam, gostam muito de ver o São Gonçalo dançando e tal, e ali você como gestor não pode esquecer os outros, você tem que dar oportunidade a todo mundo da mesma forma que as pessoas gostam de ver o São Gonçalo, mas é interessante também a gente ver o Samba de Coco; são coisas que a gente tem muito bonita que as pessoas precisam conhecer, então a gen- 
te dá oportunidade a todos da mesma forma (Irineu Fontes, entrevista 14.1.2011; grifo meu).

A taieira, o cacumbi e a chegança são manifestações folclóricas diretamente relacionadas à louvação dos santos: Nossa Senhora do Rosário e são Benedito, antiga celebração festiva que foi ressignificada com a criação do Encontro Cultural, em 1976. A dança de são Gonçalo, embora não esteja associada à devoção dos santos pretos, tem aspecto religioso, pois ocorre a pedido de algum pagador de promessa. O samba de pareia, por outro lado, apesar de não estar associado ao universo religioso, remete às raízes culturais quilombolas, pois era dançada para celebrar o nascimento de um bebê na Mussuca, povoados oriundo de um dos mais fortes quilombos da região.

O prestígio simbólico desses grupos parece basear-se, assim, em sua originalidade, devido à peculiaridade de seus mitos de origem e singularidade dos seus aspectos performáticos e de sua antiguidade. A taieira, o cacumbi e a chegança são vistos nos grupos folclóricos mais antigos do município de Laranjeiras, sendo seguidos pela dança de são Gonçalo. O samba de pareia, embora não tão antigo, se destaca por ser único:

tem muito são Gonçalo por aí, mas que nem o da Mussuca não tem não, e outra, eu sei que você é pesquisadora, estudante, mas você já ouviu falar de samba de pareia em outro lugar, não o da Mussuca? Samba de coco você ouve falar aos muitos, mas samba de pareia, só tem na Mussuca" (Nadir, entrevista, 17.1.2011).

Os cinco grupos de Laranjeiras citados pelo secretário de cultura - Taieira, Chegança, Cacumbi, Dança de São Gonçalo e Samba de Pareia - embora não sejam os únicos grupos que praticam essas manifestações folclóricas já que há, por exemplo, em outras localidades do Brasil grupos que praticam taieira e a dança de são Gonçalo como a Dança de São Gonçalo em Echaporã (SP), a Taieira de Lagarto (SE) e a dança de são Gonçalo no povoado de Santa Brígida (BA), distinguem-se facilmente dos demais pela indumentária, pelas músicas, pelos toques dos tambores. Isso não ocorre, por exemplo, com os grupos que praticam reisados e os sambas de coco, todos muitos parecidos entre si, de modo que é difícil identificar sua localidade de origem. Os cinco grupos mencionados são conhecidos pela maioria dos turistas que se dirige a Laranjeiras para vê-los. Os mestres desses grupos são também muito procurados pelos turistas, pela imprensa e pelos pesquisadores.

Esses mestres sabem que são personagens fundamentais para o acontecer do Encontro Cultural, e isso faz com que eles tenham relação muito privilegiada com a prefeitura de Laranjeiras, principalmente com a Secretaria de Cultura do 
município. Porque desfrutam dessa relação, têm mais liberdade de se posicionar frente aos órgãos públicos, seja para obter vantagens, seja para contestar algo que não funcionou. Tal liberdade não é consentida a todos os grupos, como ilustra esta fala de mestre Zé Rolinha (entrevista em 14.1.2011), da Chegança: "Chegamos na sexta-feira, depois da abertura, no $\mathrm{Cras}^{9}$ para jantar, cadê comida? Cras fechado. Vamos brincar chateado? Não voltei mais lá nenhum dia, me adularam, mas eu não voltei. Isso tira o ânimo para brincar".

\section{O AUTÊNTICO E O NÃO AUTÊNTICO}

Alguns grupos folclóricos em Laranjeiras são vistos como grupos parafolclóricos, também chamados de grupos artísticos de projeção folclórica; são formados por pessoas interessadas em danças e folguedos folclóricos, mas que, segundo meus interlocutores, folcloristas e mestres de grupos folclóricos, não possuem legitimidade para ser considerados folclóricos, seja por não ter "tradição" ou continuidade no tempo, seja por imitar os grupos reconhecidos pelo saber local como folclóricos.

No universo pesquisado, os grupos parafolclóricos são considerados, pelos informantes mencionados, inautênticos, em oposição aos que possuem mito de origem convincente e têm representabilidade no universo social em que estão inseridos, sendo reconhecidos como autênticos. Além desses, há ainda outros dois outros fatores vistos no universo pesquisado que atestam autenticidade a um grupo: sua antiguidade e a idade de seus membros.

Dessa maneira, os grupos mais antigos são os que detêm "tradição", continuidade no tempo, e por isso são considerados autênticos, em oposição aos novos, "criados recentemente" conforme as palavras de meus interlocutores. Um grupo folclórico é ainda considerado autêntico quando é formado por adultos e, principalmente, pessoas idosas. Nesses casos são considerados "folclóricos de verdade". Se, em vez disso o grupo é formado por crianças e jovens, em grande parte das vezes é visto como grupo-mirim, parafolclórico e não autêntico.

Pude conversar com o fundador do grupo Cacumbi-mirim. Jorge foi secretário de Cultura do município de Laranjeiras no início da década de 1990. E há 25 anos, quando coordenava o Museu de Arte Sacra em Laranjeiras, criou o que chama de o Grupo Parafolclórico Cacumbi-mirim. "O Cacumbi-mirim foi o primeiro grupo parafolclórico de Laranjeiras; de lá para cá foram criados o São Gonçalo e o Samba de Pareia Mirim, Reisado Mirim" (Jorge, entrevista indireta, 11.1.2011). Segundo ele, quase todos os povoados do município de Laranjeiras, possuem grupos parafolclóricos. 
Os grupos considerados autênticos legitimam esse seu status colocandose em oposição a esses outros, considerados não autênticos. Presenciei uma conversa de Bárbara, mestra da Taieira, com uma pessoa que perguntava se, na Taieira, só dançavam crianças, e ela respondeu "sim, mas não é um grupo mirim não, sempre foi assim". Conversei também com dona Nadir (entrevista, 17.1.2011), mestra do Samba de Pareia do povoado de Mussuca, que informa ser o grupo de Samba de Pareia Mirim considerado parafolclórico

Porque é o grupo mais novo. O meu Reisado também é parafolclórico, não é folclórico ainda. Porque eles estão contribuindo agora, aí é para, não é mesmo o original. Original é o São Gonçalo e o Samba de Pareia, porque esse Samba de Pareia ele não é de agora não (...) foi no tempo da escravidão, então esse grupo é velho, é folclore (grifo meu).

Dessa maneira, tanto no discurso de Bárbara quanto no de dona Nadir, é o passado que atesta autenticidade e tradicionalidade a manifestações artísticas supostamente oriundas desse período "longínquo". Já que os grupos de crianças e os mais recentes não são associados a esse tempo que garante a tradição, eles não são vistos como originais. Os grupos provenientes desse tempo passado são chamados de tradicionais, autênticos, originais, sendo que essas categorias se equivalem nesse contexto social, se contrapondo aos grupos chamados de não tradicionais e inautênticos, considerados parafolclóricos.

Há, contudo, um efeito paradoxal na denominação dos grupos mirins como não originais, já que, embora eles sejam considerados "não autênticos", sua presença atesta uma continuidade futura do grupo "autêntico". Em nome da valorização do original e do autêntico, se adotam comportamentos e condutas que não são por eles mesmos considerados autênticos. Há uma descontinuidade de discurso em nome de uma continuidade cultural:

O grupo parafolclórico foi criado para alimentar os grupos autênticos, porque antigamente os jovens tinham vergonha de dançar, então se acostumasse desde criança eles iriam crescer e não iriam ter vergonha de ir para os grupos folclóricos (...) a maioria dos meninos que iniciaram no Cacumbi-mirim estão hoje na Chegança (Jorge, entrevista indireta, 11.1.2011; grifo meu).

A presença de crianças e adolescentes nas danças pode ser vista, dessa forma, como não autêntica, mas também como responsável pela continuidade do grupo tradicional. Embora pareçam duas facetas opostas, elas são complementares e determinam, juntas, o lugar dos "grupos de criança" no evento. Essa questão vai de encontro a uma premissa muito formulada no senso comum sobre cultura popular. Trago a premissa, a partir da fala de um turista que estava no 


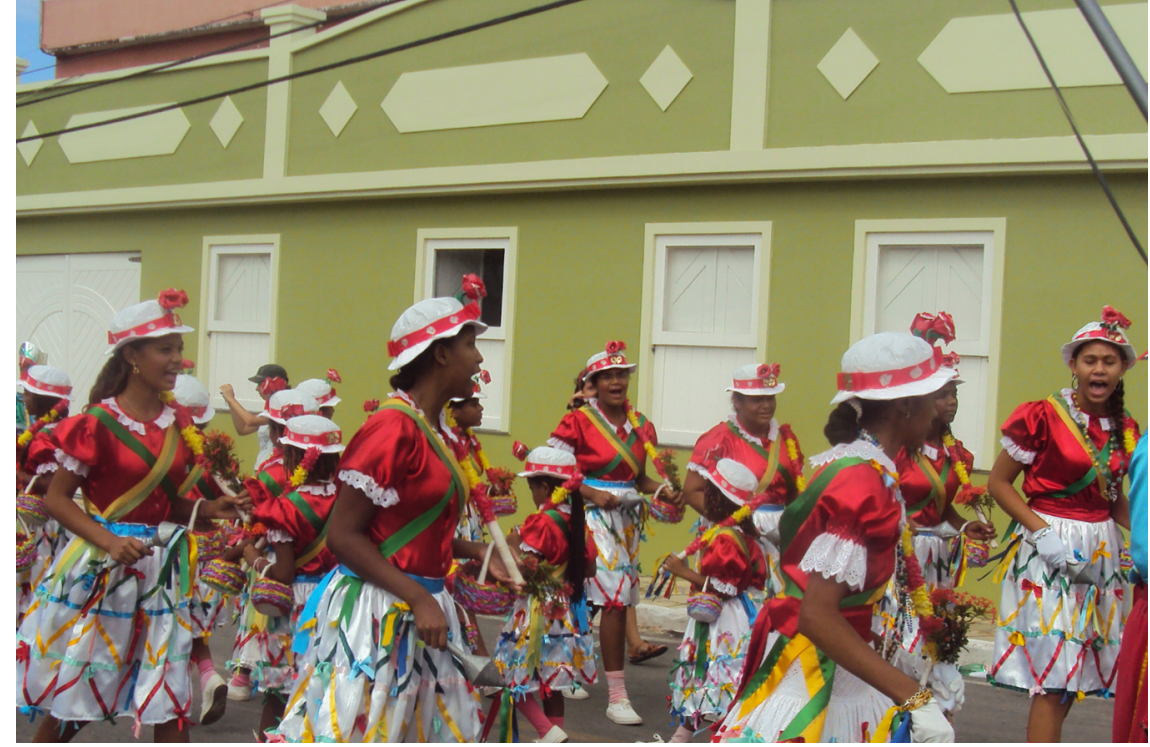

Figura 1: Taieras Fotografia: Luciana de Araujo Aguiar

Encontro Cultural de 2010. O turista de São Paulo estava hospedado em Aracaju, e um dos funcionários do hotel Ihe recomendara ir a Laranjeiras porque aquelas danças estavam acabando e logo desapareceriam. Enquanto ele me relatava o fato, havia a apresentação de um grupo de reisado; ele então olhou para mim e confirmou essa impressão: "você pode ver, é só velho que dança".

Essa imagem bem comum nas falas sobre cultura popular e folclore encontra ressonância, mas provoca efeito oposto, no evento, do qual também participam crianças. O Encontro Cultural de Laranjeiras aparece, portanto, como um espaço não só de idosos, mas também de jovens.

\section{O PRESTÍGIO SIMBÓLICO DADO PELO LUGAR DE APRESENTAÇÃO DOS GRUPOS}

A apresentação dos grupos folclóricos pode ocorrer em diversos palcos na cidade. A ideia de palco que estou trazendo não se restringe ao palanque de madeira montado para apresentações artísticas. A igreja de Nossa Senhora de Rosário e são Benedito e as ruas de Laranjeiras também o são, pois esses dois espaços permitem a performance dos grupos folclóricos, tal como o palanque de madeira montado exclusivamente para a festa.

A distinção simbólica e valorativa dos grupos se expressa também através do espaço em que se apresentam. Os grupos folclóricos de maior prestígio são aqueles ligados às celebrações festivas em homenagem a Nossa Senhora do Rosário e são Benedito, a saber: Taieira (Figura 1), Cacumbi (Figura 2) e Chegança (Figura 3). Esses grupos se apresentam na igreja de Nossa Senhora do Rosário e são Benedito. Além desses, a Dança de São Gonçalo e o Samba de Pareia pos- 


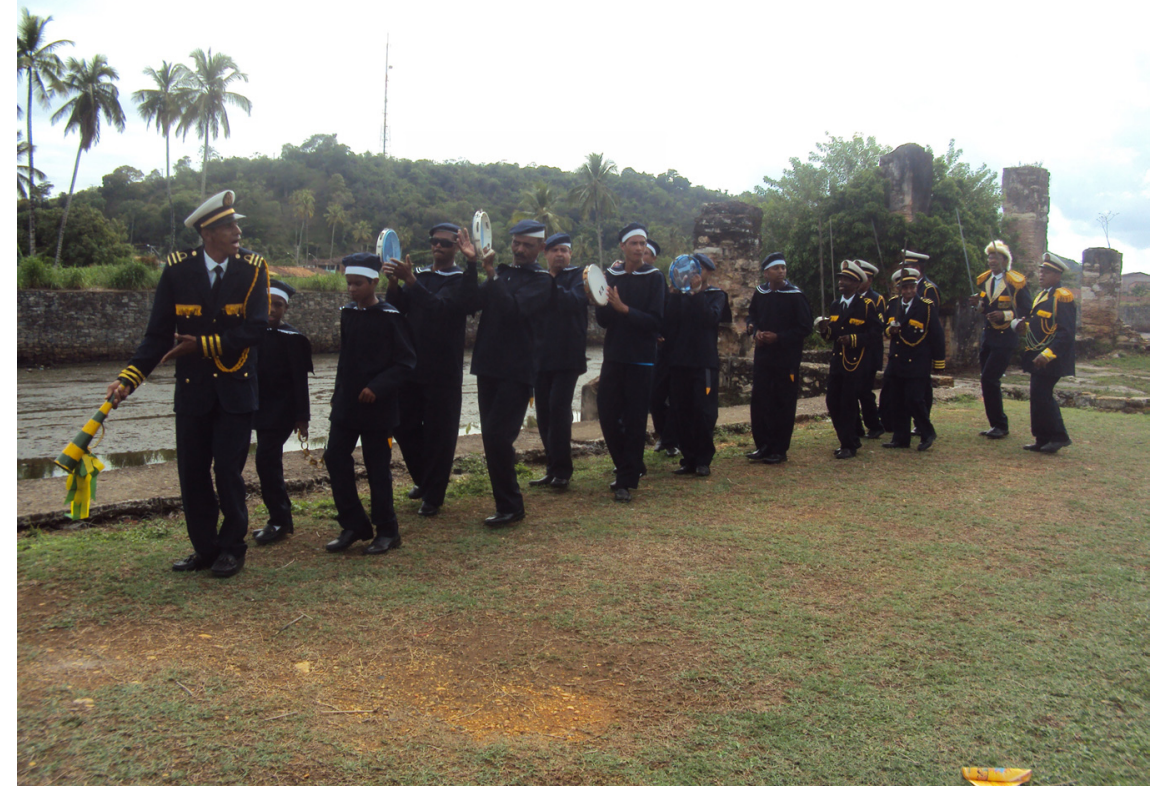

Figura 3: Chegança Fotografia: Luciana de Araujo Aguiar

A coroação da rainha das taieiras e a apresentação do Cacumbi e da Chegança na missa em homenagem a Nossa Senhora do Rosário e são Benedito constitiuem o momento mais importante do Encontro Cultural para quem vai lá reverenciar os "grupos folclóricos". Eles são "a menina dos olhos" dos órgãos públicos municipais e das autoridades eclesiais, apesar de sua forte ligação com a religião afro, como é o caso da taieira. Porque já se apresentam na igreja e em um dos momentos mais importantes do evento, eles não reclamam a apresentação nos palanques montados ao longo da cidade e também não fazem cortejos pelas ruas.

A Dança de São Gonçalo e o Samba de Pareia, por outro lado, obtêm prestígio por se apresentar no palanque e pelo glamour daí derivado. Segundo seu Sales (entrevista em 17.1.2011), mestre da Dança de São Gonçalo, "o Brasil inteiro conhece a gente, e as pessoas que vêm para o Encontro Cultural é para ver o São Gonçalo dançando". Porque possuem, como a Taieira, o Cacumbi e a Chegança, elevado status simbólico, a maioria dos turistas tem conhecimento da existência desses dois grupos, e seus dirigentes são também procurados pela imprensa e pelos pesquisadores. Esse status simbólico elevado os leva a não dançar em cortejo pelas ruas, e como não dançam também na igreja, seu lugar de apresentação é o palanque.

Os grupos que são de fora do município e se apresentam em cortejo pelas ruas alcançam prestígio pelo próprio dançar nas ruas, o que demanda ter tempo para dançar. Em relação a isso, é ilustrativa a fala da dirigente do Guerreiro ${ }^{10}$ Santo Amaro, de Santo Amaro das Brotas (SE), responsável pela organização da dança, aborrecida porque, em sua opinião, o encontro estava muito desorganizado: 
"eu gosto de dançar, não só de sair correndo em desfile; quando a gente para um pouquinho para dançar, eles já vêm dizendo, 'anda, anda'."

Esses grupos, sem nenhuma ligação com a louvação dos santos pretos, vêm apresentar-se em Laranjeiras porque recebem cachê para isso, motivo pelo qual, aliás, têm status simbólico menor em relação aos demais. Os turistas não dão conta exatamente dessas características e se posicionam de maneiras diferentes. Alguns consideram positivas as apresentações em cortejo, como uma turista baiana, argumentando ser essa a melhor forma de mostrar muitos grupos folclóricos diferentes em poucos dias. Outros, porém, a criticam, como um turista egípcio, a quem elas pareceram ser um catálogo: "temos isso, isso e isso". Em sua opinião, as apresentações são muito rápidas, e afirmou que poderia ficar um dia inteiro assistindo a uma dança para a conhecer de verdade e não só para ver pessoas de um grupo de dança passando em cortejo.

Os mestres desses grupos não são procurados nem pela imprensa nem por pesquisadores, e são de alguma forma desconhecidos pelos órgãos públicos municipais e autoridades eclesiais. Porque recebem para dançar nas ruas, de alguma forma se satisfazem e não reclamam a apresentação nos palanques.

As apresentações dos grupos folclóricos atraem majoritariamente turistas e pesquisadores, seja em cortejo nas ruas, na Igreja de Nossa Senhora do Rosário ou nos palcos. As que ocorrem nestes dois últimos espaços, entretanto, atraem mais pessoas da população local do que os cortejos.

Essa leitura nos permite pensar o espaço urbano como investido com valores próprios e por isso participando ativa e não passivamente na produção de sujeitos e de relações sociais (LÉVI-STRAUSS, 1957). A igreja, considerada eminentemente um espaço sagrado, atrai para si manifestações folclóricas envolvidas em um universo religioso e que são valorizadas positivamente naquele contexto. Palco das manifestações consolidadas na cidade como religiosas, ela não só as atrai como apoia os grupos, como evidencia a homilia do padre na missa em homenagem a Nossa Senhora do Rosário e são Benedito em 10 de janeiro de 2010:

Saudamos a Taieira, saudamos o Cacumbi, saudamos todos os demais grupos da nossa cidade, visitantes, saudamos o povo de Deus (...) secretário geral do Encontro lone Sobral, secretário de Cultura Irineu Fontes, secretário Paulo Leite, os demais secretários que participaram, grupos folclóricos da nossa cidade, a Chegança na pessoa de Zé Rolinha, o Cacumbi na pessoa de seu Deca, a Taieira na pessoa de Bárbara, a todos os grupos da nossa cidade e aos grupos visitantes (...) É a cultura do povo que se torna cada vez mais visível nesse ponto alto da festa do Encontro Cultural, por isso, que- 
ridos irmãos e irmãs dos grupos folclóricos, aceite, divulgue, faça com que cada grupo se torne cada vez mais conhecido, porque vocês arrastam consigo não somente o grupo, mas toda a cidade de Laranjeiras que torna-se conhecida culturalmente não porque faz esse grande encontro mas porque deixa-se aceitar durante todo o ano a cultura do seu povo.

O palanque e a rua, por outro lado, são vistos como espaços mais profanos, sendo, portanto, palcos de manifestações que não possuem nenhuma relação com os contextos originais da Festa dos Santos Reis. O par Igreja x Rua/Palanque exprime em sua polaridade uma tensão que perpassa os grupos folclóricos em apresentação no Encontro Cultural de Laranjeiras.

Podemos pensar também que a valorização mais positiva dos grupos folclóricos que se apresentam na igreja em oposição à menor valorização dos grupos que desfilam nas ruas denota a importância que as ideias cosmológicas e religiosas possuem ainda com relação aos espaços.

Sob outro ângulo, podemos pensar ainda que a igreja e o palanque sintetizam duas formas de construção de prestígio, em oposição às apresentações em cortejo pelas ruas, que não parecem promover prestígio. A igreja está inserida no regime da louvação dos santos pretos enquanto o palanque está inserido no regime do Encontro Cultural.

\section{DISPUTA PELO PRESTÍGIO SIMBÓLICO}

Tanto para o Samba de Pareia quanto para a Dança de São Gonçalo a apresentação no palanque parece ser importante como estratégia visando manter alto seu status simbólico e, de alguma maneira, disputar prestígio com os grupos "mais tradicionais" da cidade: Taieira, Cacumbi e Chegança. Esses dois grupos são os que mais prezam as apresentações em palanque, forma que, por exemplo, a Taieira recusa, considerando-a inautêntica. A Taieira, o Cacumbi e a Chegança obtêm prestígio via louvação a Nossa Senhora do Rosário na missa de domingo, o Samba de Pareia e a Dança de São Gonçalo, por sua vez, precisam do palanque para alcançar prestígio.

Os grupos chamados mais tradicionais parecem querer evitar a partilha de seu alto prestígio simbólico com os chamados menos tradicionais. Em um de meus primeiros dias de 2010 em Laranjeiras, presenciei forte crítica à Dança de São Gonçalo por se estar "espetacularizando". Conversava com uma pessoa ligada ao Cacumbi e ela declarou que o pessoal do São Gonçalo estava ficando muito esnobe porque foi para Brasília, entre outros lugares. Segundo suas palavras, eles possuem três grupos, um adulto, um mirim e um adolescente; quando um 
não vai para fora da cidade, vai outro. E, só para se apresentar no Encontro, vão receber 3.000 reais. "E os outros grupos, quanto cada um vai receber?", perguntei. "Mil reais." Descobri depois que cada grupo de são Gonçalo iria receber também 1.000 reais e, como são três, o total era de 3.000 reais.

Disputa, conflito e competição são inerentes aos processos sociais. Quando vemos as expressões da cultura popular de forma "essencializada" tendemos a pensar, de forma romantizada, que elas são puras e que as formas de competição não as atingem. Um olhar atento, porém, nos revela essa dimensão conflitiva.

\section{O PALANQUE E OS GRUPOS FOLCLÓRICOS}

A presença do palanque para as apresentações folclóricas gera muitas controvérsias entre os participantes das danças e os pesquisadores e políticos envolvidos com o Encontro. As controvérsias giram em torno de dois polos opostos: autenticidade $\mathrm{x}$ desejo de ser mais bem visto. Para alguns políticos e alguns pesquisadores, e mesmo para alguns atores da cultura popular, o palanque tira a autenticidade dos grupos folclóricos. Por outro lado, para a maioria dos participantes desses grupos, o palanque é considerado a melhor maneira de ser mais bem visto pelos espectadores.

Cito um caso ocorrido em 2010 com relação às apresentações programadas para o Palco Dona Lalinha. O primeiro dia planejado era sexta-feira, depois da abertura oficial do Encontro. Por conta de grande atraso na programação, logo após a abertura oficial, o ônibus da prefeitura levou os grupos para seus povoados, e, por isso, não houve apresentação. O outro dia planejado para essas apresentações era o domingo após a procissão. Encerrada a procissão, porém, o Palco Dona Lalinha estava sendo preparado para o show do padre Antonio Maria, cuja grande estrutura requereu exclusividade do palanque por tempo maior do que o inicialmente previsto pelos organizadores do Encontro. Os grupos folclóricos ficaram, então, sem espaço e, ao procurar orientação junto à comissão organizadora do evento, foram encaminhados para o Tablado Cultural Igreja Matriz, ${ }^{11}$ que, entretanto, já estava ocupado por apresentações de dança e teatro. Dona Nadir, mestre do Samba de Pareia, liderou, então, em favor dos grupos folclóricos, um protesto que saiu em cortejo pelas ruas, seguido por estudantes. Posteriormente, disse-me dona Nadir (entrevista em 14.1.2010):

Não fiquei satisfeita com essa festa aí não, vem um monte de gente de fora, um monte de colega pra ver a gente e nós não dança, deu aquele problema todo, o primeiro ano que aconteceu isso foi esse ano agora. (...) Esse encontro tratou os grupos folclóricos como cachorros, uma coisinha aí à toa, que não tem importância. 
Nadir acrescentou que aquilo nunca ocorrera e que era tradição do Encontro os grupos folclóricos se apresentarem no palanque. Lindolfo Amaral (entrevista em 12.1.2010), funcionário da Secretaria de Estado de Cultura, também comentou essa tradição:

Uma mudança que aconteceu ao longo dos tempos é que o palco foi crescendo (...) também temos que entender que os grupos folclóricos acabaram indo pro palco. Isso desde sempre. No primeiro encontro, realizado em maio de 1976, havia um circo; o circo tinha um picadeiro, o picadeiro não deixa de ser um palco. $E$ isso muda o espaço geográfico de apresentação; se você disser, hoje, que os grupos folclóricos vão-se apresentar no chão, eles não vão querer em Laranjeiras, porque existem palcos, no plural (...) então, se existe essa tradição que é o palco, eles desejam se apresentar da meIhor maneira possivel. Eles querem ser visíveis, eles querem que as pessoas vejam, então o palco acabou sendo inevitável. "Ah, os grupos estão perdendo as suas características". Não sei se isso perde característica não (grifo meu).

Sua posição, todavia, não é unânime. Uma fala do secretário de Cultura de Laranjeiras, Irineu Fontes (entrevista em 13.1.2010), ilustra opinião divergente:

Qual é o palco do grupo folclórico? O palco do grupo folclórico é a rua (...) Por que se colocou em palco? Porque acharam que se devia moldar o grupo ao palco. O palco que tem que se moldar ao grupo (...). Tanto que esse ano foi muito pouco grupo no palco (...) Então, o que que a gente faz na rua: dá condição técnica para que todo mundo possa ouvir o que está acontecendo. Quando você dá essa condição, microfonando, colocando piso mais baixo para que as pessoas vejam a movimentação do grupo, toda essa questão, você consegue fazer com que o palco que é a rua se transforme num palco mesmo, onde as pessoas tenham lugar para ver. Agora se você colocar num palco, com uma iluminação e um espaço deste tamanho, não é nada, não vira grupo folclórico, não vira grupo artístico, não vira nada (...) É isso que a gente tem que fazer, fazer com que dê prioridade ao que é mais importante no Encontro Cultural que é a cultura popular (grifos meus).

A ideia de autenticidade está implícita ou explicitamente indicada nessa fala. Segundo Gonçalves (2007), o autêntico é equacionado ao original, enquanto o inautêntico à cópia ou reprodução. Essa categoria, porém, só existe quando se acredita que o que está sendo referido como autêntico é algo dado, natural. Dessa maneira, os discursos em torno de uma suposta autenticidade atribuída à rua como espaço legítimo para apresentação de um grupo folclórico e as diferen- 
tes visões sobre o significado do palanque para mostra de danças ditas folclóricas não levam em conta a natureza cultural dessas construções. Quando se acredita que uma relação já é dada e não construída, atribui-se uma ideia de pureza a essa relação. Isso pode ser visto de modo muito presente nos estudos sobre o folclore brasileiro.

Canclini (apud CARVALHO, 1991, p. 7) propõe descartar a escorregadia noção de autenticidade, presente na conceituação de vários autores, e sugere o critério de "representatividade sociocultural: não importa tanto os objetos, música e hábitos tradicionais por sua capacidade de permanecerem 'puros', iguais a si mesmos, como porque representam o modo de conceber e viver daqueles que os produzem e usam".

As categorias pureza, autenticidade, ruralidade e povo associadas às manifestações do folclore levariam à conclusão aparentemente óbvia de que os grupos folclóricos deveriam apresentar-se na rua, já que parece ser autêntica, por oposição ao palanque. Quando usamos essas nossas categorias classificatórias, hierarquizamos as expressões culturais a partir de um sistema de valores constituído dentro de um certo contexto ideológico. À medida, portanto, que nos deslocamos para o que as pessoas que estão dançando querem, falam, pensam e desejam, vemos a questão por outro prisma. Saímos de uma visão etnocêntrica e nos direcionamos para uma visão relativizadora, buscando compreender de dentro, a partir daquele outro, seus desejos e suas aspirações.

Assim, de um lado, a apresentação dos chamados grupos folclóricos na rua parece ser autêntica. De outro lado, o que alguns integrantes dos grupos desejam é justamente mostrar suas manifestações como trabalho de arte, o que sabem fazer bem, e numa perspectiva o melhor jeito de fazer isso, na concepção de alguns deles, como dona Nadir, é no palco. Há outra questão que precisa ser posta neste debate. Por mais que pareça mais tradicional aos olhos do secretário de Cultura a apresentação dos grupos folclóricos nas ruas, a tradição criada pelo Encontro Cultural foi sua exibição em palanque, como apontado por Lindolfo Amaral.

Diferente dos grupos que se apresentaram na igreja e no cortejo, o Samba de Pareia e a Dança de São Gonçalo em 2010 não se apresentaram em lugar nenhum, só participando do cortejo na abertura oficial do evento e da procissão no domingo, sem apresentações específicas, salvo nas casas de algumas pessoas que os convidaram a dançar. Embora tenham sido pagos mesmo sem se apresentar, lutaram por isso, pois o prestígio, nesse contexto, parece ocorrer não na esfera econômica, mas na esfera simbólica. Por isso, dona Nadir e seu Sales, mes- 
tre da Dança de São Gonçalo, foram os mestres de grupos folclóricos que mais se aborreceram com a não apresentação em palanque.

\section{CONSIDERAÇÕES FINAIS}

A diferença de prestígio obtido junto à população de Laranjeiras, a turistas, pesquisadores e pessoas ligadas a órgãos públicos de Laranjeiras e de Sergipe pelos grupos que se apresentam no Encontro Cultural de Laranjeiras acaba construindo uma hierarquia simbólica entre eles que passa por diferentes planos, idade, antiguidade, lugar de apresentação, patrocínio, entre outros.

Os critérios que constroem essa hierarquia não são acionados juntos; são acionados e reivindicados por diferentes pessoas em diferentes contextos, a partir da estrutura do evento e da relação entre os atores (GLUCKMAN, 1987). Esses critérios podem ser explícitos ou implícitos e revelam negociações de hierarquia de prestígio e de autenticidade. Negociações que, como vimos, se manifestam de maneira bastante ativa no contexto do Encontro Cultural.

\section{REFERÊNCIAS BIBLIOGRÁFICAS}

CANCLINI, Néstor García. Las Culturas Populares en el Capitalismo. México: Editorial Nueva Imagem, 1982.

CARVALHO, José Jorge. As duas faces da tradição. O clássico e o popular na Modernidade latino-americana. Brasília: UnB, 1991. (Série Antropologia, n. 109)

DANTAS, Beatriz Góis. A taieira de Sergipe - pesquisa exaustiva sobre uma dança tradicional do nordeste. Petrópolis: Vozes, 1972.

GLUCKMAN, Max. Análise de uma situação social na Zululândia moderna. In: FELDMAN-BIANCO, Bela (Org.). A antropologia das sociedades contemporâneas. São Paulo: Global,1987.

GONÇALVES, José Reginaldo Santos. Antropologia dos objetos:coleções, museus e patrimônios. Rio de Janeiro: Iphan, 2007.

LÉVI-STRAUSS, Claude: “Zona Pioneira” In: Tristes Trópicos. São Paulo: Editora Anhembi Limitada. 1957.

SCHECHNER, Richard. “O que é performance?”. In: Performance Studies: An Introduccion. New York \& London: Routledge, p. 28-51, 2006.

TURINO, Thomas. Music as social life: the politics of participation. Chicago. University of Chicago Press, 2008.

TURNER, Victor. The Anthropology of Performance. New York: PAJ Publications, 1987. 


\section{NOTAS}

1 Este artigo é parte de minha dissertação de mestrado intitulada Celebração e estudo de folclore brasileiro: o Encontro Cultural de Laranjeiras (SE), defendida em junho de 2011 pelo Programa de Pós-Graduação em Sociologia e Antropologia da UFRJ e orientada pela professora doutora Maria Laura V.C. Cavalcanti.

2 Folguedo formado por grupo intitulado batalhão ou tropa, subordinado a um sargento. Os participantes portam bacamartes que são utilizados nos festejos natalinos e juninos para dar tiros de pólvora seca. Podem ser acompanhados por banda de pífanos ou zabumbas que se encarregam da parte musical. Fonte: http://www.cnfcp.gov.br/tesauro/00001895.htm Acesso em 14.8.2012.

3 Dança de conjunto cujos participantes executam coreografia de passos acelerados, fazendo grandes círculos e girando ao mesmo tempo em torno de si, com habilidade perfeita e precisa, cadenciada pelo som da batida de um zabumba. Na cidade de Lagarto, em Sergipe, só os homens dançam. No final dos versos, fazem uma curta série de voltas, terminada por um staccato e batida forte de pé. Fonte: http://www.cnfcp.com.br/tesauro/00001722.htm Acesso em 14.8.2012.

4 Folguedo de características variadas que dramatiza as dificuldades vividas pelos portugueses durante as conquistas - corsários, calmaria, motim e tempestade. Em algumas variantes inclui também o combate entre cristãos e mouros, quando aparecem ainda um rei mouro, seus embaixadores e princesas. Os personagens vestem uniformes da Marinha, segundo o escalão militar, podendo também figurar nas apresentações, dois palhaços, um padre, um doutor, por exemplo. Fonte: http://www.cnfcp.com.br/tesauro/00002050.htm Acesso em 14.8.2012.

5 Dança de pares de origem portuguesa, em louvor a são Gonçalo do Amarante, organizada geralmente em pagamento de promessa ou voto de devoção. Em frente ao altar com a imagem do santo, formam-se duas fileiras, podendo ser de mulheres, de homens ou de homens e mulheres, encabeçadas por dois violeiros - mestre e contramestre. A dança é dividida em partes ou jornadas. Os dançarinos se alternam cantando a uma só voz e fazendo movimentos para a esquerda e para a direita. No final, podem formar uma roda em que o promesseiro dança segurando a imagem do santo retirada do altar, ou, no caso de haver apenas uma imagem para vários promesseiros, o santo vai passando de mão em mão. Em Laranjeiras o fecho é dado pela chula de encerramento, com as duas fileiras, ora se aproximando, ora se afastando, chegando diante do altar, onde todos se ajoelham, fazem vênia e dão por encerrada a dança. Fonte: http://www.cnfcp.com.br/tesauro/00000094.htm Acesso em 14.8.2012. 
60 samba de pareia parece derivar do nome parelha por ter formação de dois pares que se destacam e se sucedem na roda. O samba de pareia ocorre sempre que nasce uma criança na comunidade quilombola de Mussuca, em Laranjeiras. O objetivo é manifestar a alegria do grupo com a chegada do recém-nascido. A dança naquela região é relatada como surgida na época áurea dos engenhos de cana-de-açúcar. $\mathrm{O}$ samba de pareia tem um ritmo parecido com o samba de coco. Fonte: http://sitedobareta.com.br/municipios/sambade-pareia-leva-a-cultura-de-laranjeiras-a-assembleia-legislativa-26-03-2011/ acesso em 16.7.2012

7 Congada com ocorrência em localidades do Nordeste e Sul do Brasil. O enredo apresenta variações, mas em geral alude aos reis Congo e Bamba e homenageia Nossa Senhora do Rosário e são Benedito, sendo composto de cantos de chegada, louvores religiosos, cantos soltos e uma parte de guerra entre os dois reis. Os cantos são denominados marchas e marchas-fogo e são acompanhados por música de pandeiro e batuque de tambores em várias toadas. Em Santa Catarina, representa a revolta de marinheiros que cobram do capitão o dinheiro da ração; formam-se duas alas de marinheiros trajados com calças azuis e camisas brancas, sapatos brancos e chapéus enfeitados por quatro fitas, tendo ao centro o capitão, que desempenha o papel de chamador. Fonte: http://www.cnfcp.com.br/tesauro/00002062.htm Acesso em 14.8.2012.

8 A taieira, segundo a coordenadora do grupo, é um ritual de coroação de Nossa Senhora do Rosário. As taieiras são meninas que dançam para louvar a Virgem. Além das taieiras, o ritual é composto ainda por outros personagens: as rainhas, personagens que são coroadas junto com Nossa Senhora do Rosário na missa, as lacraias (mulheres que seguram sombrinhas debaixo das quais seguem as rainhas), o rei, o ministro (que é quem acompanha o rei) capacete (menino que faz guarda ao rei) e o patrão, que é o tocador do tambor, instrumento que marca o ritmo dos cânticos. Segundo Dantas (1972, p. 58), a taieira tem relação direta com o reinado dos congos: reis e rainhas escolhidos através das irmandades de Nossa Senhora do Rosário e com a permissão das autoridades civis e religiosas durante o período escravocrata brasileiro. "Para a coroação desses reis, cujo mandato era anual ou vitalício, organizavam-se festas e pomposos cortejos, que os acompanhavam até a Igreja onde eram coroados pelo padre. A dança da taieira, como outras danças-cortejos, derivaria desses acompanhamentos reais."

9 Centro de Referência de Assistência Social. É na sede do Cras de Laranjeiras que, durante o Encontro Cultural de Laranjeiras, são servidas as refeições para os grupos folclóricos que participam do evento.

10 Reisado surgido na década de 1930 em Alagoas. De caráter dramático profano-religioso, é comemorado entre 24 de dezembro e 6 de janeiro, anunciando de porta em porta a chegada do Messias e homenageando os três Reis 
Magos. Com número de componentes variando entre 25 e 35, o folguedo se compõe de elementos dos reisados e caboclinhos. Consta de uma sequência de cantigas dançadas por bailarinos em trajes multicores. Alguns personagens: mestre, contramestre, rainha (às vezes são três), lira, índio Peri e seus vassalos, embaixadores, palhaços. Fonte: http://www.cnfcp.com.br/ tesauro/00002058.htm Acesso em 14.8.2012.

11 Palco montado pela prefeitura para as atividades do Encontro Cultural.

Luciana de Araujo Aguiar é bacharel e licenciada em ciências sociais pela UFRJ e mestre em sociologia com concentração em antropologia pelo Programa de Pós-Graduação em Sociologia e Antropologia da UFRJ.

Recebido em: 01/06/2012

Aceito em: 08/08/2012 